\title{
Trajetória acadêmica de uma estudante com deficiência visual no ensino superior
}

\author{
Lisiê Marlene da Silveira Melo Martins \\ Luzia Guacira dos Santos Silva \\ Universidade Federal do Rio Grande do Norte
}

\section{Resumo}

Este artigo constitui um recorte de pesquisa de mestrado e tem como objetivo apresentar o processo educacional de uma aluna com deficiência visual - baixa visão no Ensino Superior, durante o seu primeiro semestre letivo, em um curso de engenharia da UFRN. A análise de sua trajetória acadêmica aponta que, embora o caso estudado faça parte de uma realidade em que há uma política institucional que contempla a temática da inclusão, ainda se faz necessário avançar nas questões relativas às práticas e mediação pedagógicas que atendam às especificidades de aprendizagem de discentes em tal condição de deficiência, assim como em relação à formação continuada dos docentes numa perspectiva inclusiva e ao estreitamento das relações intersetoriais quanto ao acompanhamento educacional a tais estudantes.

Palavras-chave: Ensino superior. Educação inclusiva. Deficiência visual.

\section{Academic career of a student with visual impairment in higher education}

\section{Abstract}

This paper is a master degree research clipping, which aims to investigate and discuss the impressions of a student with visual impairments - low vision, on the first semester in an engineering course in UFRN. The analysis of his academic career points out that, although the case study is part of a reality, in which there is an institutional policy that includes the issue of inclusion, is still necessary to move forward on issues related to teaching practices and mediation that meet the specific learning of students in such a condition of disability. As well as in relation to the continuing education of teachers in an inclusive perspective and the strengthening of inter-sectoral relations and the educational support to such students.

Keywords: Higher education. Inclusive education. Visual impairment. 
Trajetória acadêmica de uma estudante com deficiência visual no ensino superior

\section{Carrera académica de un estudiante con discapacidad visual en enseñanza superior}

\section{Resumen}

Este artículo es un recorte de una investigación en la maestría en educación y tiene como objetivo investigar y discutir las impresiones de una estudiante con discapacidad visual - baja visión - en el primer semestre de un curso de ingeniería en la UFRN. El análisis de su carrera académica señala que, aunque el estudio de caso es parte de una realidad donde existe una política institucional que incluye el tema de la inclusión, sigue siendo necesario avanzar en cuestiones relacionadas con las prácticas de enseñanza y de mediación que cumplen con el aprendizaje específico de estudiantes en una condición de discapacidad visual. Así como en la formación continuada de los profesores en una perspectiva inclusiva y el fortalecimiento de las relaciones intersectoriales en la categoría de apoyo educativo para estos estudiantes.

Palabras clave: Enseñanza superior. Educación inclusiva. Deficiencia visual.

\section{Introdução}

Ao analisarmos o cenário educacional brasileiro, é possível observar que, nestes últimos anos, ocorreram, no Brasil, relevantes mudanças nas concepções teóricas sobre a questão da deficiência e sobre a pessoa com deficiência, consequentemente, sobre seu vínculo com as Instituições de Ensino Superior - IES.

Tal realidade tem se apresentado como um desafio ao desenvolvimento de políiticas e ações que garantam aos alunos com deficiência, bem como àqueles com transtorno global do desenvolvimento e altas habilidades/ superdotação - público-alvo da Educação Especial, o exercício pleno da cidadania e a democratização do acesso a esse nível de ensino. Isto traz às Instituições de Ensino Superior a responsabilidade de se reorganizarem para receber esses estudantes, garantindo-lhes, de forma isonômica, tanto a formação como uma educação de qualidade.

Em 201 1, de acordo com dados do Instituto Nacional de Estudos e Pesquisas Educacionais Anísio Teixeira - Inep (BRASIL, 2013), o Brasil contava com aproximadamente 6,7 milhões de alunos matriculados no ensino superior, e destes, apenas 23.250 são considerados alunos com deficiência. Se 
comparados ao montante de alunos matriculados, nesse nível de ensino, podemos perceber que há uma grande distância quantitativa, pois a população de universitários com deficiência representa, apenas, cerca de 0,3\% desse grupo.

Além dos números, os estudos realizados sobre a temática da inclusão de estudantes - público-alvo da educação especial, no ensino superior brasileiro - têm revelado resultados acerca da realidade desse processo em termos de acessibilidade ISANTOS, 2012 ; MELO, SARAIVA, SOUZA, 2013 ; SANTOS, 2012), ingresso, acesso e permanência (NEGRY, 2012; CASTRO, 2011; GUERREIRO, 2011 1), políticas de inclusão/serviços de apoio (FERREIRA, 2012; SOUZA, 2010), trajetórias/experiência (VIANA, 2010; ROSSETTO, 2009).

Embora estejam sendo ampliadas as discussões e as políticas sobre a inclusão no Ensino Superior, bem como tenham ocorrido mudanças de atitudes e tratamento dados aos estudantes com deficiência, nesse nível de ensino, ressaltamos que ainda são poucos os estudos que trazem, como protagonismo, a fala de estudantes com deficiência, o que, a nosso ver, é um aspecto importante a ser considerado, haja vista serem os principais atores desse processo.

Com essa perspectiva, buscamos escutar o que uma estudante com deficiência visual - baixa visão, tem a dizer a respeito do seu processo educacional, no primeiro semestre de seu curso de graduação, na Universidade Federal do Rio Grande do Norte (UFRN). Com isso, buscamos não apenas retratar a realidade vivenciada por tal estudante no ensino superior, mas, sobretudo, na contribuição que a sua experiência pode trazer para reflexões e ações institucionais, visando à efetiva inclusão de alunos em sua condição de deficiência, no âmbito da UFRN e demais instituições de ensino superior.

\section{Fundamentação teórica}

No contexto nacional, nos últimos anos, vêm ganhando destaque as políticas de democratização da educação no Ensino Superior, através de ações afirmativas que visam ao acesso e à inclusão do público-alvo da Educação Especial nesse nível de ensino.

Tais ações têm tomado, como alicerces fundamentais, documentos que versam sobre o direito de todos à Educação, em todos os níveis e modalidades de ensino, tais como: a Declaração Mundial de Educação para Todos (TAILÂNDIA, 1990); a Declaração Mundial sobre Necessidades Educativas 
Especiais (BRASIL, 1994); a Declaração Universal dos Direitos Humanos de 1948, ratificada no Brasil como Emenda Constitucional Emenda Constitucional n 45/2004 (ONU, 1948); a Lei 9.394, de 20 de dezembro de 1996, das Diretrizes e Bases da Educação (BRASIL, 1996) e a Convenção sobre os Direitos das Pessoas com Deficiência (BRASIL, 2006).

Especificamente sobre a democratização do Ensino Superior, atualmente, destacamos o Programa de Apoio a Planos e Reestruturação e Expansão das Universidades Federais (REUNI), pelo Decreto nº 6.096, de 24 de abril de 2007; o Decreto n 7.234, de 19 de julho de 2010, que dispõe sobre o Programa Nacional de Assistência Estudantil (PNAES); o Decreto n 7.611 , de 17 de novembro de 2011 , que dispõe sobre o Atendimento Educacional Especializado (AEE), nas Instituições Federais de Ensino Superior.

Podemos destacar, ainda, nas ações de políticas de acessibilidade, - Programa Incluir, criado, em 2005, pelo Ministério da Educação (MEC), por meio do Sistema de Seleção Unificada (SiSU) e Secretaria de Educação Continuada, Alfabetização, Diversidade e Inclusão (SECADI), visando fomentar a criação e a consolidação de núcleos de acessibilidade nas Instituições Federais de Ensino Superior - IFES, as quais respondem pela organização 254 de ações institucionais que garantam a inclusão de pessoas com deficiência na vida acadêmica, eliminando barreiras pedagógicas, arquitetônicas e de comunicação e informação, promovendo o cumprimento dos requisitos legais de acessibilidade.

Corroborando as perspectivas políticas e pedagógicas nacionais, a Universidade Federal do Rio Grande do Norte (UFRN) tem buscado, ao longo dos anos, ampliar a participação no processo de inclusão do público-alvo da Educação Especial: pessoas com deficiência, pessoas com transtornos globais do desenvolvimento, com altas habilidades e superdotação, e transtornos específicos de aprendizagem referidas nos documentos dessa instituição como pessoas com necessidades educacionais especiais no ensino superior. Destacamos, nesses documentos, o compromisso com uma política institucional que privilegia a inserção social como uma de suas políticas estruturantes e a recusa a toda e qualquer barreira que se contraponha à cultura do respeito à diversidade humana. Tal fato pode ser observado no Plano de Desenvolvimento Institucional 2010-2019, com destaque para ações inclusivas institucionais que visem: 
Eliminar toda e qualquer forma de barreira (seja ela pedagógica, ambiental, atitudinal, comunicacional, entre outras) tem sido uma ação permanente da instituição em prol da criação de uma cultura de respeito à diversidade, garantindo as condições de acessibilidade, de tecnologias apropriadas e de recursos humanos qualificados, de tal forma que possibilitem a construção de um modelo de política educacional inclusiva que atenda às necessidades educacionais especiais dos estudantes que demandarem por apoios específicos em sua formação acadêmica (UNIVERSIDADE FEDERAL DO RIO GRANDE DO NORTE, 2010, p. 70).

Concernentes às ações de promoção da inclusão de alunos com deficiência na UFRN, podemos destacar ações institucionais que perpassaram os pilares do ensino, pesquisa e extensão, fomentando a discussão sobre a inclusão de estudantes com deficiência e assegurando-thes o acesso e a permanência no contexto universitário.

Como exemplos, citamos: a articulação da Pró-reitoria de Graduação - PROGRAD, com a Comissão Permanente de Vestibular - COMPERVE, para a adequação dos processos seletivos às necessidades específicas dos candidatos com deficiência em consonância com as orientações do Decreto n. 3.298, de 20 de dezembro de 1999; a instalação do Núcleo de Acessibilidade, denominado de Comissão Permanente de Apoio ao Estudante com Necessidades Educacionais Especiais - CAENE, pela Portaria n ${ }^{\circ} 203$, de 15 de março de 2010; a elaboração da Resolução n 193, de 21 de setembro de 2010, CONSEPE, que dispõe sobre o atendimento educacional a estudantes com necessidades educacionais especiais - NEE, na UFRN; a elaboração de um capítulo específico sobre atendimento às pessoas com NEE no Plano de Desenvolvimento Institucional 2010-2019 e a inserção no Regulamento dos Cursos de Graduação (CONSEPE) Resolução n 171, de 5 de novembro de 2013, assegurando, no Art. 335, direitos para o atendimento educacional, condizente com as necessidades educacionais especiais de cada estudante com NEE, mediante a:

Disponibilização de mediadores (ledores e escribas) para a compreensão da escrita e da fala nas atividades acadêmicas (quando requerido pelo aluno); adaptação do material pedagógico e dos equipamentos; orientações sobre metodologia de ensino adaptada; orientações sobre formas adaptadas de avaliação do rendimento acadêmico e de correção dos instrumentos 
de avaliação, de acordo com a necessidade do aluno; e tempo adicional de 50\% (cinquenta por cento) para a realização das atividades de avaliação que tem duração limitada, conforme a NEE apresentada (UNIVERSIDADE FEDERAL DO RIO GRANDE DO NORTE, 2013 , p. 54).

Compondo a promoção do processo educacional inclusivo no âmbito institucional, ocorreu, também, a aprovação de três projetos junto ao MEC dentro do Programa Incluir: a criação do Laboratório de Acessibilidade' a estruturação do serviço de acompanhamento acadêmico com a contratação de profissionais específicos e a aquisição de equipamentos de tecnologia assistiva.

Podemos, ainda, ressaltar a abertura de processo seletivo para a concessão de Bolsas de Tutoria Inclusiva por meio dos Editais n 002, de 16 de outubro de 2014; e reeditado em 21 de março de 2016 através do edital $n^{\circ} 001 / 2016$. Ressaltamos, também, o lançamento do Programa de Bolsa Acessibilidade, por meio do Edital $n^{\circ} 163$, em $1^{\circ}$ de outubro de 2014; que prevê a concessão de bolsas, destinadas aos estudantes com deficiência de graduação presencial da UFRN, que se encontram em condições de vulnerabi256 lidade socioeconômica.

trabalho realizado pelo Núcleo de Acessibilidade (CAENE), por sua vez, tem como finalidade a garantia dos direitos, bem como o estímulo à reivindicação por justiça social e pelos direitos de cidadania, por parte da população de estudantes com NEE. Essas ações são executadas através da consolidação de redes de apoio e serviço institucional, trabalhando para a promoção de práticas cidadãs na comunidade universitária, propondo ações para a eliminação de barreiras arquitetônicas, atitudinais, pedagógicas e de comunicação na UFRN, visando garantir o acesso, a permanência e a conclusão dos cursos com pleno sucesso.

Em face desse cenário, podemos perceber que a política educacional brasileira e as políticas institucionais na UFRN desbravam caminhos para as possibilidades de efetivação do processo de inclusão de pessoas com deficiência no ensino superior, apontando a seguridade de oportunidades para que realizem um curso superior com garantias legais de acesso, permanência e conclusão, com êxito acadêmico. 
Para Amaral (1998), a Universidade exerce grande importância na concretização das propostas de uma educação inclusiva que remonta todos os níveis e modalidades educacionais:

Hoje, com os avanços relativos ao papel da educação na construção e exercício da cidadania de todas as pessoas e com a importância que se atribui à educação continuada, somos levados a discutir o papel das Universidades para garantir a presença e participação de pessoas com deficiência nos seus quadros docente, discente e de funcionários não docentes (AMARAL, 1998, p. 2).

Desta forma, a universidade desempenha um papel relevante na busca pela reconstrução do que compreendemos socialmente sobre a pessoa com deficiência, numa perspectiva mais crítica e pautada em princípios como o da democratização das oportunidades de superação das dificuldades. Assim, é possível perceber o sujeito pleno de potenciais, possibilidades, capaz de romper com as limitações, superando ações excludentes, compreendendo, assim, que "[...] a presença de pessoas com deficiência na universidade é, pois, um processo interativo, assegurado pelos direitos dessas pessoas à igualdade de oportunidades e à participação social" (AMARAL, 1998, p. 3).

Não se trata apenas de garantir o direito ao acesso, mas também pensar no desenvolvimento de estratégias, no uso de recursos tecnológicos e pedagógicos para promover a participação efetiva e a permanência com efetivo sucesso. É necessário reconhecer o direito à igualdade de oportunidades, criando alternativas pedagógicas adequadas e distintas que equiparem as condições de pessoas que não se encontram em condições de deficiência. Compreendemos que a permanência em cursos em nível superior implica a possibilidade de usufruir dos espaços, recursos tecnológicos e educacionais em igualdade de condições, oferecidas aos demais alunos da instituição.

Sobre as políticas de Educação Inclusiva, concordamos com Pires e Pires (2011) quando afirmam que

Esta preocupação com políticas de inclusão no ensino superior, em nosso país, é bem vinda, e aponta para uma nova tendência de democratização do ensino superior em termos de atendimento à diversidade e à inclusão. Se tradicionalmente o debate e as práticas da educação inclusiva se realizavam, em grande maioria, no âmbito da educação básica, não se pode esquecer que o ensino 
superior é um espaço em que a inclusão é prevista em nossa legislação, e deve ser efetivada com oferta de condições de formação e qualidade para todos os estudantes do ensino superior (PIRES; PIRES, 2011 , p. 1291.

As ações e práticas inclusivas no Ensino Superior envolvem a articulação de uma gama de instrumentos e estratégias para promoção da inclusão. Dentre elas, podemos elencar a elaboração e implementação de políticas institucionais, a democratização ao acesso na oferta de vagas aos estudantes com deficiência, acessibilidade física e informacional. Podemos, ainda, citar a necessária formação continuada dos docentes, a qual deve pautar-se nos princípios da Educação Inclusiva, uma vez que a atitude e as práticas desses profissionais são cruciais para a superação das barreiras que impedem a efetivação da inclusão em sala de aula.

Esses são elementos estruturantes que demandam reflexão e discussão coletiva, pois qualquer mudança para dar suporte à implementação de políticas públicas ou de políticas sociais requer transformações nas atitudes e ações de seus partícipes. Logo, percebemos que os atores sociais público-alvo da educação especial estão em busca da materialização das atuais políticas educacionais, uma vez que elas se apresentam como novas oportunidades de deslocamento político-social.

A expansão do ensino através da democratização do acesso de alunos público-alvo da Educação Especial no ensino comum, nessa perspectiva, deve ser vista com atenção para que não se transforme em uma espécie de inclusão fictícia no âmbito das IFES, onde poderá imperar uma inclusão mascarada que mantém o aluno com deficiência visual, por exemplo, à margem do conhecimento, por meio de práticas educativas que ferem os princípios de equidade, da igualdade, da participação ativa no processo educacional.

Embora possamos apontar os avanços históricos, políticos e educacionais, ainda temos conhecimento de situações, envolvendo estudantes com deficiência que veem, cotidianamente, os seus direitos garantidos, ao ingressarem nas universidades, apenas por força da lei. É comum ocorrer a negação de vagas, bem como a falta de sensibilidade por parte de docentes que negam ao aluno com deficiência adaptações didáticas em detrimento da acessibilidade a que têm direito. 
Por essa razão, consideramos de suma importância que exista um trabalho formativo inicial (nos cursos de iniciação à docência), e continuado e permanente (ao longo dos semestres letivos) direcionado aos docentes nas universidades. Tal formação deve ser focada em metodologias que atrelem teoria e prática, que sejam diversificadas, críticas, e concernentes com os princípios da educação inclusiva, no intuito de garantir a permanência dos alunos com deficiência visual, e, em geral, nos cursos de graduação e de pós-graduação.

Nesse sentido, ensina Freire (1996) que

[...] a prática docente crítica, implicante do pensar certo, envolve o movimento dinâmico, dialético entre o fazer e o pensar sobre o fazer. [...] Por isso é que na formação permanente dos professores, o momento fundamental é o da reflexão crítica sobre a prática. É pensando criticamente a prática de hoje ou de ontem que se pode melhorar a próxima prática (FREIRE, 1996, p. 38-39).

Concordamos com Silva (2014) quando afirma que o professor precisa preparar-se para vivenciar a inclusão educacional de alunos com deficiência, não apenas quanto às adequações à metodologia empregada e aos procedimentos didáticos, mas também, quanto aos instrumentos e recursos metodológicos a utilizar, às diferentes maneiras de enxergar e suas implicações para o processo de aprendizagem daqueles estudantes. Assim, terá subsídios para planejar as suas atividades contemplando a flexibilização dos objetivos, dos conteúdos e dos métodos avaliativos, na busca por evitar o insucesso acadêmico de tais estudantes, que necessitam estar e sentir-se incluídos em ambientes que propiciem o seu desenvolvimento pleno, sua condição emancipatória, tanto no viés acadêmico quanto no humanístico e social.

Nesse sentido, Rui Canário (2006) ressalta a importância da responsabilidade assumida pelo professor no tocante à preocupação com uma prática docente para a formação integral de todos os estudantes, afirmando que

[... é nesse quadro que aumenta a importância da educação e a responsabilidade dos educadores. Pede-se à educação, entendida em um sentido amplo, como um processo de conhecer e intervir no mundo, uma contribuição decisiva para que possamos encontrar uma "saída" para as questões de civilização que nos atingem. A resposta a este tipo de desafio implica concepções e práticas 
educativas que valorizem uma função crítica e emancipatória (CANÁRIO, 2006, p. 12).

Assim, ao refletirmos sobre a democratização do ensino superior e da garantia de acesso à pessoa com deficiência visual, constatamos a responsabilidade fundamental e os desafios que as instituições de ensino superior e os seus professores assumiram, bem como a necessidade de reestruturação do seu paradigma de atuação. Afinar-se com os parâmetros da educação inclusiva pressupõe direcionar as ações para a aceitação da diversidade, garantindo a aprendizagem de seus alunos e respeitando suas especificidades.

\section{Metodologia}

Na pesquisa desenvolvida, adotamos uma abordagem qualitativa, utilizando o método de Estudo de Caso. De acordo com Marconi e Lakatos (2004), esse tipo de abordagem descreve a complexidade do comportamento humano e fornece uma análise mais detalhada sobre as investigações, hábitos, atitudes, tendências de comportamento, entre outros aspectos. $O$ método de 260 Estudo de Caso, por sua vez, permite o conhecimento amplo e detalhado de um ou poucos objetos, mediante estudo profundo e exaustivo, tarefa praticamente impossível através de outros tipos de delineamentos considerados (GIL, 1994).

Este estudo foi submetido e aprovado $\left(n^{\circ} 4785971\right.$ 5. 1.0000.5292) pelo Comitê de Ética em Pesquisa do Hospital Universitário Onofre Lopes (HUOL/UFRN), em consonância com a Resolução CNS n 466, de 12 de dezembro de 2012, por se tratar de uma pesquisa com seres humanos.

A pesquisa foi desenvolvida na Universidade Federal do Rio Grande do Norte (UFRN), na cidade do Natal, com 7 docentes e 5 discentes. Para fins deste artigo, apresentaremos, apenas, os dados de uma das participantes, estudante de um dos cursos de Engenharia. Optamos em não discriminar qual das Engenharias a aluna cursa, para preservar sua identidade. Ela tem 20 anos e apresenta um quadro de deficiência visual - baixa visão, com sinais clínicos de Ceratocone².

A baixa visão, condição de deficiência da estudante, não pode ser corrigida através de lentes normais, sendo necessário, para o atendimento de 
suas necessidades específicas, o uso de materiais impressos ampliados ou o auxílio de potentes recursos ópticos. Sendo assim, as dificuldades visuais da aluna, a quem passaremos a nominar pelo nome fictício - Cláudia, não são corrigidas em nível funcional por meio de óculos normais ou apenas se aproximando do foco a ser visualizado.

Ela apresenta dificuldades para realizar leituras de textos com letras impressas em tamanho convencional, sendo possível enxergar as letras se ampliadas para o tamanho 28, em fonte Arial black ou Tahoma. Mesmo com a ampliação do material impresso, Cláudia apresenta dificuldades para realizar leituras por tempo prolongado, pois cansa a visão facilmente devido ao esforço realizado. Além disso, a claridade a impede de visualizar letras e imagens em ambientes abertos ou muito iluminados, como, por exemplo, os registros realizados pelos professores na lousa, principalmente, com canetas de cores claras.

Para a obtenção dos dados, utilizamos como instrumento a entrevista, apoiada pelo "formulário de acompanhamento semestral", utilizado no Núcleo de Acessibilidade (CAENE), em que se registram informações sobre o desenvolvimento acadêmico dos alunos atendidos pela Comissão.

A escolha do caso, aqui apresentado, deu-se a partir da adequação dos critérios utilizados para selecionar os participantes da pesquisa, a saber: ser estudante de curso de graduação na UFRN, ter solicitado apoio à CAENE e ter deficiência visual.

No semestre de 2015.1 a estudante Cláudia solicitou apoio ao Núcleo de Acessibilidade da UFRN - CAENE, a fim de receber acompanhamento educacional individual para que fossem dadas orientações pedagógicas aos seus professores sobre como lidar com a sua condição de deficiência e, ainda, para ter acesso à adaptação de materiais de forma a atender a sua maneira específica de enxergar.

Após a triagem do caso pela equipe técnico-educacional da CAENE, discussão e análise dos laudos médicos por ela apresentados, a aluna teve a sua solicitação de apoio deferida. Em seguida, foi realizada entrevista pedagógica com ela, visando conhecer como ocorreu seu processo de escolarização, a origem de sua deficiência, a escolha pelo curso de graduação e as suas expectativas em relação à graduação. 
Também foi realizada uma avaliação funcional da visão com o objetivo de conhecer os aspectos práticos de sua acuidade visual, no tocante aos tipos e tamanhos de letras impressas, contrastes de cores, sensibilidade à luminosidade, entre outras questões. Após todo esse levantamento de informações elaborou-se, em parceria com a aluna, um documento denominado "Parecer Técnico", com as informações gerais do caso e as orientações didático-pedagógicas que, posteriormente, foi lançado no Sistema Integrado de Gestão de Atividades Acadêmicas (SIGAA), e encaminhado por E-mail à coordenação e aos professores que estariam ministrando disciplinas a ela, nesse período.

Durante todo o semestre letivo, foi realizado o acompanhamento educacional da aluna Cláudia, através de encontros pedagógicos para a avaliação das estratégias sugeridas, orientações quanto ao uso de recursos de tecnologia assistiva, acompanhamento da produção e adaptação de materiais didáticos junto ao Laboratório de Acessibilidade. Também foi oferecida aos docentes a possibilidade de encontros pedagógicos para auxiliá-los no desenvolvimento do trabalho junto à aluna. No entanto, não se obteve retorno à oferta, ocasionando a não concretização de tais encontros.

Ao final do semestre, Cláudia respondeu a um formulário de acompa262 nhamento com o objetivo de avaliar os serviços oferecidos pela instituição à sua condição de aluna com deficiência visual. Nesse formulário, a aluna pôde relatar e analisar o seu processo educacional inclusivo no primeiro semestre de 2015, no que se refere ao seu próprio desempenho acadêmico; a acessibilidade informacional e apoios oferecidos pela CAENE, professores, orientador acadêmico e coordenação do curso. Com base em suas respostas, foi possível traçar um novo plano de ação para o semestre seguinte. Tal formulário foi o instrumento utilizado para a análise dos dados aqui apresentados, conforme já sinalizado, considerando aspectos da Análise de discurso (ORLANDI, 2009).

\section{Análise dos dados}

Com base em referenciais teóricos que conduziram o processo reflexivo a respeito da inclusão de estudantes com deficiência visual no Ensino Superior e, em particular, o caso da estudante com baixa visão, Cláudia, teceremos a análise acerca do seu processo educacional inclusivo, durante o primeiro semestre letivo de 2015, na UFRN. 
Para organizar as informações levantadas, decidimos elencar as temáticas respondidas por Cláudia em uma sequência alfabética a fim de facilitar a compreensão e sistematização desta análise:

a) Apoios Institucionais: Ao ser questionada sobre os apoios institucionais recebidos ao longo do semestre, a aluna relatou que:

O único apoio recebido é pela CAENE, que sempre me ajuda e informa aos professores a minha situação. $\bigcirc$ que melhora um pouco a relação com alguns professores [...] A coordenação nunca manteve nenhum contato e o orientador acadêmico, não conheço (CLÁUDIA, 2015).

É interessante frisar mediante a afirmação da aluna que o estabelecimento de redes de apoios institucionais se apresenta em primeira necessidade, pois, de acordo com Melo (2014), esse é o caminho para oferecer ao aluno com deficiência um melhor suporte institucional, descaracterizando a equivocada impressão de exclusiva responsabilidade aos setores que trabalham com inclusão e acessibilidade. Nesse caso, a rede de apoio deveria ser mais bem articulada entre a CAENE, a coordenação do curso e o corpo docente, visando à implementação de estratégias para que a aluna obtivesse melhor êxito acadêmico.

b) Apoio dos professores: Sobre o recebimento de apoio por parte dos professores, a aluna afirmou:

Como minha deficiência não é perceptível logo quando a pessoa me vê, os professores não se importavam com as minhas necessidades, acho que se eu usasse uma cadeira de rodas ou fosse cega mesmo, eles iriam me ver (CLÁUDIA, 2015).

Essa fala de Cláudia nos remete à noção dos estereótipos impressos à pessoa com deficiência. Nas relações interpessoais, o estigma é imputado nas mais diversas situações, sendo, de acordo com Goffman (1963), as pessoas categorizadas pelos seus atributos, marcadas pelas características físicas, comportamentais ou de inserção tribais que fogem dos padrões de normalidade da sociedade.

Diante da situação apontada pela estudante, ressalta ao nosso olhar a ausência de aproximação por parte dos docentes e a colocação da aluna em 
relação a sua própria deficiência, julgando patamares mais ou menos importantes de acordo com o estereótipo impingido a cada condição de deficiência.

Neste sentido, Adorno e Horkheimer (apud COSTA, 2014, p. 4) destacam a necessidade da dialética do esclarecimento, na qual "[...] a atividade do sujeito com deficiência seria aproximar-se e o assemelhar-se [... $]^{\prime \prime}$ e não se afastar e desejar modificar a sua condição. Assim, tratando-se de preconceito é possível afirmar, baseados em Costa (2014), que a sua matéria-prima é o desconhecimento.

Continuando na temática "Apoio por parte dos professores" descrevemos mais dois depoimentos da estudante Cláudia:

No dia da prova um professor trouxe a avaliação em tamanho normal para que eu fizesse. Me desesperei, não conseguia ver nada! Lembrei a ele que não podia ver e perguntei se ele se lembrava das orientações do parecer da CAENE. Ele disse que havia esquecido, que depois eu faria a prova. Me senti desrespeitada. Estudei, me preparei para fazer a prova naquele dia e ele me negou o direito que eu tinha de fazer a prova igual aos meus colegas [...] em outra situação o professor também não levou a prova ampliada e me mandou fazer em dupla, só porque eu não via o que estava escrito. Todo o resto da turma fez individual, só eu é que fiz em dupla. Me senti novamente desrespeitada (CLÁUDIA, 2015).

Às vezes o professor até quer fazer o certo, mas expõe a pessoa. Uma professora me constrangeu diante de toda a turma perguntando pelo meu nome e disse: Aquela que é doente, que não vê nada! [...] A professora mudou todos os slides da aula dela, com os contrastes que foram orientados no parecer. Eu conseguia ver tudo [...] minha maior dificuldade é acompanhar a aula de um professor que escreve no quadro. Eu não consigo enxergar nada. [...] não são todos os professores que entendem a situação, e na maioria dos casos, poucos vem conversar para saber mais das dificuldades (CLÁUDIA, 2015).

A primeira fala da aluna demonstra a não compreensão e o desrespeito ao que está posto na legislação brasileira sobre o direito ao acesso à informação (BRASIL, 2015). O fato de a estudante não receber as avaliações com letras impressas em formato acessível, impõe-se como uma barreira ao seu processo educacional inclusivo, porque são desconsideradas, naqueles momentos, as especificidades de sua condição. 
Os professores precisam estar mais atentos à diversidade de alunos em sua sala de aula e ao cumprimento do que regulamentam as políticas nacionais e institucionais sobre os direitos dos estudantes com deficiência. Frisamos que, neste caso da aluna em referência, não se pode afirmar desconhecimento, pois, no início do semestre, cada docente foi comunicado sobre as necessidades específicas da aluna em virtude de sua deficiência visual e a disponibilização de serviços para adaptação de materiais, inclusive das avaliações.

No entanto, mediante as observações feitas em relação a algumas atitudes dos docentes frente a estudantes com deficiência, consideramos que a inclusão destes no ensino superior vem propor novas perspectivas sobre o pensar e agir do professor quer seja no ato de planejar e ensinar, quer seja em compreender o processo de aprendizagem e avaliar o ensino universitário e o desempenho dos alunos.

O docente é levado a ultrapassar as barreiras historicamente impostas pelo modelo tradicional de transmissão do saber de modo linear e cartesiano. E, nesse movimento, é conduzido a refletir sobre suas ações na adoção de metodologias de ensino que possibilitem a aprendizagem significativa por parte de todos os seus alunos.

E assim, como afirma Mansini, citado por Silva (2013, p. 67), perceber a necessidade de "[...] desfazer barreiras e construir possibilidades no caminho do aluno, de um lado ampliando sua percepção e compreensão dos conhecimentos, de outro, intensificando suas relações e comunicações com os que o cercam".

Sobre a relação professor-aluno, compreendemos que as atitudes individuais são determinantes nas relações interpessoais e está nelas a possibilidade de sensibilização e aproximação. Assim, apoiadas em Amaral (1998), podemos considerar que as barreiras impostas por outros constituem o grande entrave ao processo inclusivo ora vivido pela sociedade contemporânea.

Ao compartilharmos um espaço democrático, misto e pulsante como a universidade, é necessário o compromisso com o humano e com o olhar sensível às relações. E assim, como nos conduz a pensar Ainscow (2009, p. 14), devemos "[...] responder positivamente a diversidade, considerando as diferenças não como problemas a serem consertados, mas como oportunidades de enriquecer o aprendizado". 
Trajetória acadêmica de uma estudante com deficiência visual no ensino superior

Sigamos, com mais uma temática.

c) Apoio por parte da CAENE - Ao ser questionada sobre avaliação do processo de apoio por parte da CAENE, a aluna afirmou:

A CAENE sempre faz o possível para ajudar e melhorar as dificuldades, sempre me orientando nas atividades de curso, me ofereceu um tutor e sempre está disponível a conversar com os meus professores (CLÁUDIA, 2015).

A presença dos núcleos de acessibilidade nas Instituições Federais de Ensino Superior - IFES é realidade muito recente no Brasil. O Programa Incluir, lançado pelo Ministério de Educação - MEC/ Secretaria de Educação Especial - SEESP em 2005, apresentou-se como ação afirmativa com o objetivo de fomentar a criação e consolidação dos núcleos de acessibilidade.

Na Universidade Federal do Rio Grande do Norte (UFRN), a institucionalização da CAENE surge como importante passo para a promoção do processo educacional inclusivo, que, de acordo com Melo (2014), tem como um dos objetivos

[...] intervir e acompanhar, na perspectiva interdisciplinar, a trajetória do estudante com NEE na UFRN, mediando o suporte educacional para o desenvolvimento de seu processo de ensino-aprendizagem (MELO, 2014, p. 360).

Nesse ponto, o trabalho relacionado ao apoio educacional, às orientações acadêmicas e à mediação pedagógica entre docente e discente apresentam-se como fatores essenciais à permanência e conclusão do curso de graduação, com êxito, pelos alunos com deficiência.

d) Sugestões para a promoção da inclusão na UFRN - Ao ser questionada sobre novos apoios, sugestões e outras ações para a promoção da inclusão na UFRN, Cláudia levantou a temática da formação continuada aos docentes:

Os professores desconhecem que tem um aluno com baixa visão e também não sabem como agir! [...] eu acredito que alguns professores erram por não quererem fazer o certo com a gente mesmo, mas outros fazem por não conhecer as nossas necessidades, por falta de informação e não sabem como lidar com um aluno 
deficiente. Acho que eles deveriam fazer cursos e se reciclarem nessa área também (CLÁUDIA, 2015).

Mediante as sugestões da aluna, inferimos que o processo de formação na perspectiva inclusiva, aos docentes da UFRN, carece da elaboração de uma proposta de formação continuada e permanente que thes possibilite realizar um trabalho pedagógico condizente com as particularidades de acesso ao conhecimento por parte de alunos com deficiência visual, entre outros. Magalhães (2013) complementa essa ideia, considerando que os programas de formação inicial e continuada devem tornar aptos os docentes a ações educativas menos segregadoras e preconceituosas tornando-as mais respeitosas e inclusivas.

\section{Considerações finais}

Este trabalho teve o propósito de apresentar o processo educacional de uma aluna com deficiência visual - baixa visão no Ensino Superior, durante o seu primeiro semestre letivo no ano de 2015, em um curso de engenharia da UFRN. Diante dos dados levantados, foram analisados aspectos relacionados ao seu desempenho acadêmico, apoios institucionais oferecidos pelo setor de atendimento educacional especializado - a CAENE, professores, coordenação do curso, e consideradas sugestões dadas pela aluna, para a promoção da inclusão de pessoas com deficiência na instituição.

Diante dos dados analisados, pudemos compreender que a inclusão de estudantes com deficiência no Ensino Superior, e especificamente, no caso estudado, a deficiência visual cujo campo é a UFRN, apresenta-se como processo em construção, necessitando de uma observação mais atenta às ações desenvolvidas na promoção da inclusão, via práticas de ensino.

Que a oferta permanente de cursos sobre a temática da inclusão no Ensino Superior nos programas de aperfeiçoamento relacionados à pedagogia universitária em uma perspectiva inclusiva precisa ser uma ação constante na instituição, oportunizando a troca de experiências, a relação constante entre teoria e prática, a discussão sobre a renovação das metodologias, considerando a diversidade dos alunos, em particular, daqueles com deficiência visual. 
Por mais que o caso apresentado faça parte de uma realidade institucional em que há uma política que contempla a temática da inclusão e um núcleo de acessibilidade para promover ações inclusivas, consideramos que ainda é necessário avançar em aspectos relacionados à mediação pedagógica, à formação continuada dos professores voltada a uma perspectiva inclusiva e ao estreitamento das relações intersetoriais no tocante ao acompanhamento de estudantes com deficiência. Tudo isto com vistas a assegurar e garantir a todo o estudante com deficiência o direito a uma formação de qualidade, em igualdade de condições e oportunidades.

Portanto, compreendemos que, no contexto da UFRN, há necessidade de se conhecer e reelaborar as novas fases desse processo inclusivo, perspectivando o envolvimento de todos que dela fazem parte, desde o momento em que o aluno com deficiência se encontra na condição de candidato ao ingresso, até a conclusão do seu Curso.

Destacamos que, embora este estudo se trate de uma realidade específica, alguns entraves ao processo inclusivo ora apresentados também são semelhantemente relatados por outros estudos realizados em diversas universidades brasileiras, a saber: Santos, 2012; Negry, 2012; Castro, 2011 ; 268 Guerreiro, 2011 ; Ferreira, 2012; Souza, 2010; Viana, 2010; Rossetto, 2009. Portanto, acreditamos ser necessária uma análise mais profunda sobre o processo educacional inclusivo nas Universidades brasileiras, onde possamos ter acesso a um panorama da atual situação nas Instituições Federais de Ensino Superior no tocante às políticas institucionais, ações dos núcleos de acessibilidade e formação dos professores.

Logo, a importância em levar a efeito outros trabalhos cujo foco seja a análise de um panorama nacional das IFES sobre essa temática, e ainda as impressões da pessoa com deficiência acerca da inclusão no Ensino Superior, poderão trazer importantes contribuições na elaboração de ações prospectivas e de fomento de políticas educacionais no contexto das Universidades.

\section{Notas}

1 Laboratório de Acessibilidade é espaço que tem como principal objetivo democratizar e garantir a acessibilidade informacional, através de equipamentos de tecnologia assistiva voltados para o atendimento aos estudantes com deficiências e transtornos de aprendizagens da UFRN. Neste espaço é realizada a adaptação de materiais bibliográficos das disciplinas, bem como os 
materiais complementares, de acordo com as demandas e necessidades específicas dos alunos acompanhados pela CAENE.

2 O ceratocone é um distúrbio chamado distrofia contínua e progressiva, que ocorre na córnea com afinamento central ou paracentral, geralmente inferior, resultando no abaulamento anterior da córnea, na forma de cone. A apresentação é geralmente bilateral e assimétrica. Está associada a baixa de visão geralmente por alta miopia e astigmatismo. (http://www.cbo.net.br/novo/ publico-geral/ceratocone.php) Acesso em 20 mar. 2016.

\section{Referências}

AINSCOW, Mel. Tornar a educação inclusiva: como essa tarefa deve ser conceituada? In: FÁVERO, Osmar; FERREIRA, Windyz; IRELAND, Timothy; BARREIROS, Débora (Org.). Tornar a educação inclusiva. Brasília: UNESCO, 2009.

AMARAL, Lígia Assumpção. Sobre crocodilos e avestruzes: falando de diferenças físicas, preconceitos e sua superação. In: Júlio Groppa Aquino (Org.). Diferenças e preconceitos na escola: alternativas teóricas e Práticas. São Paulo: Summus, 1998.

BRASIL. Declaração de Salamanca e linha de ação sobre necessidades educativas especiais. Brasília: UNESCO, 1994.

Lei $\mathbf{n}^{\circ}$ 9.394, de 20 de dezembro de 1996. Estabelece as Diretrizes e Bases da Educação Nacional. Ministério da Educação. Brasília. 1996.

Decreto $\mathbf{n}^{\circ}$ 3.298, de 20 de dezembro de 1999. Dispõe sobre a Política Nacional para a Integração da Pessoa Portadora de Deficiência, consolida as normas de proteção, e dá outras providências. Brasília, 1999.

Convenção sobre os Direitos das Pessoas com Deficiência. Protocolo facultativo à convenção sobre os Direitos das Pessoas com Deficiência: Brasília, Secretaria de Direitos Humanos, Secretaria Nacional de Promoção dos Direitos da Pessoa com Deficiência. Brasília, 2006.

Decreto $\mathbf{n}^{\circ}$ 7.234, de 19 de julho de 2010. Dispõe sobre o Programa Nacional de Assistência Estudantil - PNAES. Ministério da Educação. Secretaria de Educação Especial Brasília, 2010.

Decreto $n^{0} 7.611$, de 17 de novembro de 2011. Dispõe sobre o Atendimento Educacional Especializado. Ministério da Educação. Diário Oficial da União. Brasília-DF, 2011 . Disponível em: <http://www.planalto.gov.br/ccivil_03/_Ato2011-2014/2011/ Decreto/D761 1.htm > Acesso em: 10 dez. 2011. 
Decreto $\mathbf{n}^{\circ}$ 6.096, de $\mathbf{2 4}$ de abril de 2007. Institui o Programa de Apoio a Planos de Reestruturação e Expansão das Universidades Federais - REUNI, Ministério da Educação. Secretaria de Educação Especial. Brasília: Ministério da Educação, 2007.

Programa Incluir. Brasília: Ministério da Educação. Secretaria de Educação Especial, 2004. Disponível em: http://portal.mec.gov.br/sesu/index.php?option=content \&task=view\&id=557\&ltemid=303. Acesso em: 21 maio 2014.

Instituto Nacional de Estudos e Pesquisas Educacionais Anísio Teixeira. Censo da educação superior: 2011 - resumo técnico. Brasília: Instituto Nacional de Estudos e Pesquisas Educacionais Anísio Teixeira, 2013.

Lei $\mathbf{n}^{\circ}$ 13. 146, de 6 de julho de 2015. Institui a Lei brasileira de inclusão da pessoa com deficiência (Estatuto da pessoa com deficiência). Disponível em: http://www. planalto. gov.br/ccivil_03/_Ato2015-2018/2015/Lei/L13146.htm Acesso em: 17 jul. 2016

CANÁRIO, Rui. A escola tem futuro? Das promessas às incertezas. Porto Alegre: Artmed, 2006.

CASTRO, Sabrina Fernandes. Ingresso e permanência de alunos com deficiência em universidades públicas brasileiras. 201 1. 278f. Tese (Doutorado em Educação) - Programa

270 de Pós-Graduação em Educação Especial, Universidade Federal de São Carlos, São Carlos, 2011.

COSTA, Valdelúcia Alves da. Diferença, desvio, preconceito e estigma: a questão da deficiência. 2014. Disponível em: <http://www.asdef.com.br/innova/assets/artigos/historiaO 1 1.pdf>. Acesso em: 21 maio 2014.

CLÁUDIA. Entrevista. Natal (Rio Grande do Norte), 24 jul. 2015.

FERREIRA, Maria Nilma Cardoso. Educação inclusiva no ensino superior: análise das políticas educacionais para a pessoa com deficiência na Universidade Federal do Maranhão. 2012. 125f. Dissertação (Mestrado em Educação) - Programa de Pós-Graduação em Educação, Universidade Federal do Maranhão, São Luís, 2012.

FREIRE. Paulo. Pedagogia da autonomia: saberes necessários à prática educativa. São Paulo: Paz e Terra, 1996.

GOFFMAN, Erving. Estigma: notas sobre a manipulação da identidade deteriorada. Rio de Janeiro: Zahar, 1963.

GUERREIRO, Elaine Maria Bessa Rebello. Avaliação da satisfação do aluno com deficiência no ensino superior: estudo de caso da UFSCar. 23 If. 2011 . Tese (Doutorado em 
Educação) - Pós-Graduação em Educação Especial, Universidade Federal de São Carlos, São Carlos, 2011.

GIL, Antônio Carlos. Métodos e técnicas de pesquisa social. 4. ed. São Paulo: Atlas, 1994.

MAGALHÃES, Rita de Cassia Barbosa Paiva. Currículo e inclusão de alunos com deficiência no ensino superior: reflexões sobre a docência universitária. In: MELO, Francisco Ricardo Lins Vieira (Org.). Inclusão no ensino superior: docência e necessidades educacionais especiais. Natal: EDUFRN, 2013.

MARCONI, Marina de Andrade; LAKATOS, Eva Maria. Metodologia científica. 4. ed. São Paulo: Atlas, 2004.

MELO, Francisco Ricardo Lins Vieira de; SARAIVA, Luzia Livia de Oliveira; SOUSA, Nilberto. Gomes de. A Comissão Permanente de Apoio a Estudantes com Necessidades Educacionais Especiais e os desdobramentos da acessibilidade física na UFRN. In: SEMINÁRIO INTERNACIONAL INCLUSÃO EM EDUCAÇÃO: UNIVERSIDADE E PARTICIPAÇÃO, 3; 2013 , Rio de Janeiro. Anais... Rio de Janeiro, 2013.

MELO, Francisco Ricardo Lins Vieira de. Núcleo de acessibilidade e o apoio a estudantes com necessidades educacionais especiais na Universidade Federal do Rio Grande do Norte. In: MARTINS. Lúcia de Araújo Ramos, PIRES. Gláucia; PIRES. José (Org.). Caminhos para uma educação inclusiva: políticas, práticas e apoios especializados. João Pessoa: Ideia, 2014.

NEGRY, Karla Christina Pereira. Situação de deficiência: a realidade de instituições de ensino superior particulares do Distrito Federal à luz do atendimento prestado aos jovens estudantes com deficiência visual (cegos). 2012. $119 f$. Dissertação (Mestrado em Educação) - Programa de Pós-graduação em Educação. Universidade Católica de Brasília, 2012.

ORGANIZAÇÃO das Nações Unidas. Declaração Universal dos Direitos do Homem. Aprovada na Assembleia Geral das Nações Unidas, pela resolução 217 A (III) de 10 de dezembro de 1948.

Disponível em: http://www.onu-brasil.org.br/documentos_direitoshumanos.php. Acesso em: 19 out. 2014.

OlIVEIRA, Edja Renata Marques de; MELO Francisco Ricardo Lins Vieira de; ELALl, Gleice Virgínia Medeiros de Azambuja. Acessibilidade e participação de estudantes com deficiência física na Universidade Federal do Rio Grande do Norte. Revista Educação em Questão, Natal, v. 33, n. 19, p. 63-87, set./dez. 2008. 
Trajetória acadêmica de uma estudante com deficiência visual no ensino superior

ORLANDI, Eni Puccinelli. Análise de discurso: princípios e procedimentos. 8. ed. Campinas: Pontes, 2009.

PIRES, José; PIRES, Gláucia Nascimento da Luz. Práticas de educação e de formação. João Pessoa: Ideia, 2011 .

ROSSETTO, Elizabeth. Sujeitos com deficiência no ensino superior: vozes e significados. 2009. 238f. Tese (Doutorado em Educação) - Programa de Pós-Graduação em Educação. Universidade Federal do Rio Grande do Sul, 2009.

SANTOS, Antônio Carlos Nogueira. Acessibilidade da pessoa com deficiência física: $\bigcirc$ caso da Universidade Federal de Sergipe. Cidade Universitária Professor José Aloísio de Campos. $2012.244 f$. Dissertação (Mestrado em Educação) - Núcleo de Pós-Graduação em Educação. Universidade Federal de Sergipe. São Cristóvão, 2012.

SANTOS, Andreza Souza. A inclusão de estudantes com deficiência nas instituições de ensino superior da cidade de Natal/RN: análise das condições oferecidas no processo seletivo Vestibular. 2012. 138f. Dissertação (Mestrado em Educação) - Programa de PósGraduação Educação Universidade Federal do Rio Grande do Norte. Centro de Educação. Natal, 2012.

272 SILVA, Luzia Guacira Santos. Orientações didáticas para a atuação pedagógica junto a estudantes com deficiência visual no ensino superior. In: MELO, Francisco Ricardo Lins Vieira (Org.). Inclusão no ensino superior: docência e necessidades educacionais especiais. Natal: EDUFRN, 2013.

Por uma escola sem exclusões: intervenções pedagógicas junto estudantes cegos e com baixa visão. In: MARTINS. Lúcia de Araújo Ramos, PIRES. Gláucia; PIRES. José (Org.). Caminhos para uma educação inclusiva: Políticas, práticas e apoios especializados. João Pessoa: Ideia, p. 235-261, 2014.

SOUZA, Bianca Costa Silva de. Programa Incluir (2005-2009): uma iniciativa governamental de educação especial para a educação superior no Brasil. 20 10. Dissertação (Mestrado em Educação) - Programa de Pós-Graduação em Educação, Universidade Federal de Santa Catarina, Florianópolis, 2010.

TAILÂNDIA. Declaração Mundial sobre Educação para Todos: plano de ação para satisfazer as necessidades básicas de aprendizagem. UNESCO, Jomtiem/Tailândia, 1990.

UNIVERSIDADE FEDERAL DO RIO GRANDE DO NORTE. Resolução $\mathbf{n}^{\circ}$ 193, de 21 de setembro de 2010. Dispõe sobre o atendimento educacional especial aos estudantes com 
NEE na UFRN. Natal: CONSEPE, 2010. Disponível em: http://www.caene.ufrn.br/legislacao.php\#I 1/RESOLUÇÃO\%20N\%20193\%20(1).pdf> Acesso em: 31 maio 2014.

Portaria ${ }^{\circ}$ 203, de 15 de março de 2010. Dispõe sobre a instituição da Comissão Permanente de Apoio ao Estudante com Necessidades Educacionais Especiais - CAENE. Natal, 2010.

Resolução ${ }^{\circ}$ 171, de 5 de novembro de 2013. Regulamento dos cursos regulares de graduação da UFRN. Natal: CONSEPE, 2013.

Edital n 002, de 16 de outubro de 2014. Processo Seletivo de Bolsa de Tutoria Inclusiva. Nata: CONSEPE, 2014. Disponível em: http://www.sigaa.ufrn.br/sigaa/verPro ducao?idProducao=2208403\&key Acesso em: 20 out. 2014.

Edital $\mathrm{n}^{\circ}$ 163, de $\mathbf{1}^{\circ}$ de outubro de 2014. Processo Seletivo de Bolsa Acessibilidade. Ministério da Educação. CONSEPE/UFRN. Natal, 2014. Disponível em: http://www. sigaa.ufrn.br/sigaa. Acesso em: 20 out. 2014.

Edital n 001 , de 21 de março de 2016. Processo Seletivo de Bolsa de Tutoria Inclusiva. Natal: CONSEPE, 2016. Disponível em: https://sistemas.ufrn.br/shared/verArquivo Acesso em: 5 jun. 2016

Resolução CNS n 466, de 12 de dezembro de 2012. Ministério da Saúde. Conselho Nacional de Saúde. Comissão Nacional de Ética em Pesquisa. Brasília, 2012.

VIANA, Márcia Rafaela Graciliano dos Santos. O processo de inclusão de pessoas com deficiência nas instituições de ensino superior de Maceió. Dissertação (Mestrado em Educação) - Programa de Pós-graduação em Educação Brasileira. Universidade Federal de Alagoas, 2010. Universidade Federal de Alagoas, 2010.

Mestranda Lisiê Marlene da Silveira Melo Martins Universidade Federal do Rio Grande do Norte Programa de Pós-Graduação em Educação Grupo (Base) de Pesquisa sobre Educação de Pessoas com Necessidades Educacionais Especiais E-mail | lisieme|@yahoo.com.br 
Artigo

Trajetória acadêmica de uma estudante com deficiência visual no ensino superior

Profa. Dra. Luzia Guacira dos Santos Silva Universidade Federal do Rio Grande do Norte Departamento de Fundamentos e Políticas da Educação

Programa de Pós-Graduação em Educação Grupo (Base) de Pesquisa sobre Educação de Pessoas com Necessidades

Educacionais Especiais

E-mail | guaciraufrn@hotmail.com

Recebido 4 jun. 2016

Aceito 26 jul. 2016 